\title{
Effects of the side of arteriovenous fistula on outcomes after coronary artery bypass surgery in hemodialysis-dependent patients
}

\author{
Yoshiyuki Takami, MD, Kazuyoshi Tajima, MD, Wataru Kato, MD, Kei Fujii, MD, Makoto Hibino, MD, \\ Hisaaki Munakata, MD, and Yoshimasa Sakai, MD
}

Objective: The aim of the study was to determine whether using the in situ internal thoracic artery (ITA) graft ipsilateral to the arteriovenous fistula adversely affects the outcomes after isolated coronary artery bypass grafting $(\mathrm{CABG})$ in the dialysis-dependent patients to answer the concerns of a possible steal and consequent myocardial ischemia.

\begin{abstract}
Methods: We categorized 155 dialysis patients undergoing isolated CABG between January 1993 and December 2011 into 108 patients (70\%, ipsilateral group) whose left anterior descending artery (LAD) was revascularized with the ITA ipsilateral to the arteriovenous fistula and 47 patients (contralateral group) whose LAD was grafted with the ITA opposite to the fistula, to compare their early and late outcomes.
\end{abstract}

Results: While $94 \%$ of the ipsilateral group had left fistula, $55 \%$ of the contralateral group had left fistulas. The LAD was grafted with the left ITA in $94 \%$ of the ipsilateral group, whereas it was grafted with left $(49 \%)$ or right $(51 \%)$ ITAs in the contralateral group. There was no significant difference in hospital mortality between the groups (ipsilateral $10.2 \%$ vs contralateral 10.6\%). After follow-up for $55 \pm 42$ months, the overall survival (ipsilateral $58 \%$ vs contralateral $65 \%$ at 5 years) and cardiac event-free rates (ipsilateral $74 \%$ vs contralateral $68 \%$ at 5 years) were also similar between the groups by log-rank tests $(P=.90$ and $P=.07)$.

Conclusions: Revascularization of the LAD using the in situ ITA graft ipsilateral to the arteriovenous fistula increases neither the operative mortality nor the risks of late death and cardiac events after isolated CABG in dialysis patients. (J Thorac Cardiovasc Surg 2014;147:619-24)

Cardiovascular disease is the principal cause of deaths in patients receiving hemodialysis (HD), more than two thirds of whom have symptomatic coronary artery disease. ${ }^{1-3}$ Increased population with renal disease and extended life expectancy of HD patients result in more HD patients, especially with diabetes mellitus (DM) and advanced age, referred for coronary revascularization. For the HD patients with multivessel disease, coronary artery bypass grafting $(\mathrm{CABG})$ may be selected on the basis of the guidelines and the previous studies demonstrating the superiority of CABG to percutaneous coronary intervention. ${ }^{4-7}$ As well as in non-HD patients, in situ internal thoracic artery (ITA) grafting to the left anterior descending artery (LAD) improves survival and freedom from major adverse cardiac events (MACE) in HD patients. ${ }^{8-11}$

However, there are concerns of a possible steal in HD patients with a functioning ITA graft and an ipsilateral arteriovenous $(\mathrm{AV})$ fistula or shunt of the upper extremity. ${ }^{12-15}$ Although no reports definitively document a coronary

\footnotetext{
From the Department of Cardiovascular Surgery, Nagoya Daini Red Cross Hospital, Nagoya, Japan.

Disclosures: Authors have nothing to disclose with regard to commercial support.

Received for publication Oct 2, 2012; revisions received Dec 11, 2012; accepted for publication Jan 14, 2013; available ahead of print Feb 11, 2013.

Address for reprints: Yoshiyuki Takami, MD, Department of Cardiovascular Surgery,

Nagoya Daini Red Cross Hospital, 2-9 Myouken-cho, Showa-ku, Nagoya

466-8650, Japan (E-mail: takami@nagoya2.jrc.or.jp).

$0022-5223 / \$ 36.00$

Copyright (c) 2014 by The American Association for Thoracic Surgery

http://dx.doi.org/10.1016/j.jtcvs.2013.01.031
}

artery steal with an ipsilateral AV fistula, there have been several reports of a steal and consequent myocardial ischemia during HD. The aim of the present study was to determine whether revascularization of the LAD using the in situ ITA graft ipsilateral to the AV fistula increases the risk of late death and MACE after isolated CABG in HD patients.

\section{METHODS}

The institutional review board approved this retrospective observational study, and the approval included a waiver of informed consent.

\section{Study Patients}

We performed isolated CABG in 159 patients with end-stage renal failure requiring $\mathrm{HD}$ ( 124 men and 35 women with a mean age of $63 \pm 8$ years) over an 18-year period between January 1993 and December 2011. They comprised $10.4 \%$ of all patients undergoing isolated CABG during the same period. They had a history of HD for $8.9 \pm 8.1$ years (range, 0.2-36 years). The major causes of end-stage renal failure included chronic glomerulonephritis $(\mathrm{n}=32,20 \%)$ and DM $(\mathrm{n}=86,54 \%)$, whereas the causes of disease in $17(11 \%)$ patients were unknown.

Among them, after excluding 4 patients who did not undergo ITA grafting to the LAD, 155 patients were included in the study to compare 108 patients (69.7\%, ipsilateral group) whose LAD was revascularized with the in situ ITA ipsilateral to the AV fistula and 47 patients $(30.3 \%$, contralateral group) whose LAD was revascularized with the in situ ITA opposite to the AV fistula.

\section{CABG and Perioperative Renal Management}

Surgical procedures of CABG were performed through a median sternotomy, after low-potassium ( $1.5 \mathrm{mEq} / \mathrm{L}) \mathrm{HD}$ for the consecutive 2 days, 


$$
\begin{aligned}
& \text { Abbreviations and Acronyms } \\
& \begin{aligned}
\text { AV } & =\text { arteriovenous } \\
\text { CABG } & =\text { coronary artery bypass grafting } \\
\text { CI } & =\text { confidence interval } \\
\text { CPB } & =\text { cardiopulmonary bypass } \\
\text { DM } & =\text { diabetes mellitus } \\
\text { HD } & =\text { hemodialysis } \\
\text { HR } & =\text { hazard ratio } \\
\text { ITA } & =\text { internal thoracic artery } \\
\text { LAD } & =\text { left anterior descending coronary artery } \\
\text { LVEF } & =\text { left ventricular ejection fraction } \\
\text { MACE } & =\text { major adverse cardiac events }
\end{aligned}
\end{aligned}
$$

except for emergency cases, to obtain serum potassium of $3.0 \mathrm{mEq} / \mathrm{L} .{ }^{16} \mathrm{In}$ our strategy, in situ bilateral ITAs were preferred for revascularization of the left coronary territory whenever possible anatomically. Right ITAs were used to revascularize the LAD by crossing the midline if necessary. However, the use of bilateral ITAs was avoided in the HD patients with DM owing to the concerns of postoperative mediastinitis. The gastroepiploic artery (GEA) was mostly used for revascularization of the right coronary arteries with more than $90 \%$ stenosis. The coronary arteries, for which ITAs and gastroepiploic arteries were not used, were bypassed using saphenous veins anastomosed with the ascending aorta.

Since 2003, CABG was preferably performed on the beating heart with off-pump technique and cardiopulmonary bypass (CPB) was used if necessary. When $\mathrm{CPB}$ was used, we performed only hemofiltration during $\mathrm{CPB}$, as in non-HD patients. By means of a hemoconcentrator incorporated into the $\mathrm{CPB}$ circuit, serum potassium less than $4.0 \mathrm{mEq} / \mathrm{L}$ and blood hemoglobin greater than $10.0 \mathrm{~g} / \mathrm{dL}$ were maintained at the end of CPB to prevent subsequent hyperkalemia. ${ }^{16} \mathrm{HD}$ was resumed on the first postoperative day in most patients, except for those with hemodynamic instability or advanced hyperkalemia, who alternatively underwent continuous venovenous hemofiltration.

\section{Data Collection and Follow-up}

The ipsilateral and contralateral groups were retrospectively compared regarding the following primary end points: hospital mortality, late overall death, and late MACE. Hospital mortality was defined as death for any reason during the same hospitalization regardless of the length. Follow-up data were obtained from hospital charts or follow-up physicians and by means of direct telephone interviews with the patients or their families. The MACE was defined as cardiac death, myocardial infarction, hospital admission owing to congestive heart failure, and repeat revascularization. Cardiac death was defined as any death related to cardiac events, including sudden death.

\section{Statistical Analysis}

Continuous variables were expressed as means \pm standard deviations and compared for differences between 2 groups with the Mann-Whitney $U$ test. Categorical variables were expressed as percentages and analyzed using the $\chi^{2}$ test or Fisher's exact test where appropriate. A multivariate logistic regression model was constructed to evaluate whether the side of the ITA was an independent predictor of hospital mortality. Long-term survival and MACE-free rate were estimated using the Kaplan-Meier method. Unadjusted comparisons of the 2 groups were made with a log-rank test. Cox proportional hazards models were also constructed to evaluate the effect of the side of ITA in the presence of potentially confounding covariates. All statistical analyses were performed with IBM SPSS Statics version 19
(IBM Corporation, Armonk, NY), calculating hazard ratios (HR), 95\% confidence intervals (CI), and levels of statistical significance.

\section{RESULTS \\ Preoperative and Operative Characteristics}

As shown in Table 1, there were no significant differences in the patient characteristics, with the exception of the side of AV fistula, between the ipsilateral and contralateral groups. Whereas $94 \%$ of the ipsilateral group had left AV fistula, $55 \%$ of the contralateral group had left AV fistulas $(P<.001)$. The locations and constructions of AV fistulas were similar between the 2 groups.

As shown in Table 2, the study patients underwent conventional $(\mathrm{n}=55,34 \%)$, on-pump beating heart $(\mathrm{n}=31$, $20 \%)$ or off-pump coronary artery bypass $(\mathrm{n}=71,46 \%)$ with distal anastomoses of $2.9 \pm 0.9$ per patient, with no significant differences between the 2 groups. With regard to the graft arrangements, in situ left ITAs were used in all patients of the ipsilateral group and were mainly grafted to the LAD. In contrast, left ITAs were used in $91 \%$ of the patients of the contralateral group and were mostly grafted to the LAD or left circumflex artery. Right ITAs were more frequently used in the contralateral group than the ipsilateral group $(60 \%$ vs $24 \% ; P<.001)$. Right ITAs were mainly anastomosed to the left circumflex artery in the ipsilateral group and to the LAD in the contralateral group. No free ITA grafts were used for the non-LAD coronary arteries. Consequently, bilateral in situ ITAs were used more frequently in the contralateral group than in the ipsilateral group ( $47 \%$ vs $24 \% ; P=.004)$. There were no significant differences in the use of gastroepiploic artery and saphenous vein graft between the 2 groups.

\section{Early Outcomes}

Hospital mortality was $10.3 \%(16 / 155)$. The mortality improved over time: $16.2 \%$ (11/68) before 2003 and $5.7 \%(5 / 87)$ after 2003 . The causes of hospital death included mediastinitis $(n=5)$, cardiac-related $(n=4)$, sepsis $(\mathrm{n}=3)$, pneumonia $(\mathrm{n}=2)$, gastrointestinal ischemia $(\mathrm{n}=1)$, and stroke $(\mathrm{n}=1)$. As shown in Table 3, there were no significant differences in the hospital mortality and the occurrence of postoperative complications, including mediastinitis and stroke, between the ipsilateral and contralateral groups. There were also no significant differences in the durations of intensive care unit stay and hospital stay between the survivors of the 2 groups.

A multivariate logistic regression analysis adjusting for 5 covariates, including left ventricular ejection fraction (LVEF) less than $40 \%$, CPB use, bilateral ITA, and postoperative mediastinitis, revealed that ipsilateral ITA grafting to the LAD was no longer a predictor for hospital mortality (HR, 0.86; 95\% CI, 0.49-1.50; $P=.59$ ). However, the variables of LVEF less than $40 \%$ (HR, 2.22; 95\% CI, $1.23-7.12 ; P=.03)$ and $\mathrm{CPB}$ use $(\mathrm{HR}, 3.27 ; 95 \% \mathrm{CI}$, 
TABLE 1. Patients characteristics of $155 \mathrm{HD}$ patients undergoing isolated CABG according to the side of AV fistula and the side of ITA grafted with the LAD

\begin{tabular}{|c|c|c|c|}
\hline & $\begin{array}{c}\text { Ipsilateral } \\
(\mathbf{n}=\mathbf{1 0 8})\end{array}$ & $\begin{array}{c}\text { Contralateral } \\
(n=47)\end{array}$ & $P$ value \\
\hline Age, $y$ & $63 \pm 8$ & $63 \pm 9$ & 1.00 \\
\hline Male, n (\%) & $88(81 \%)$ & $34(72 \%)$ & .12 \\
\hline HD duration, $\mathrm{y}$ & $8.8 \pm 7.6$ & $9.1 \pm 9.0$ & .83 \\
\hline Hypertension, $\mathrm{n}(\%)$ & $79(73 \%)$ & $35(75 \%)$ & .86 \\
\hline $\mathrm{DM}, \mathrm{n}(\%)$ & $59(55 \%)$ & $25(53 \%)$ & .84 \\
\hline Hyperlipidemia, n (\%) & $41(38 \%)$ & $19(40 \%)$ & .70 \\
\hline Smoking, $\mathrm{n}(\%)$ & $69(64 \%)$ & $29(62 \%)$ & .89 \\
\hline $\mathrm{PAD}, \mathrm{n}(\%)$ & $33(31 \%)$ & $15(32 \%)$ & .72 \\
\hline Previous CVD, n (\%) & $18(17 \%)$ & $7(15 \%)$ & .63 \\
\hline Previous MI, n (\%) & $35(32 \%)$ & $13(28 \%)$ & .53 \\
\hline History of HF, n (\%) & $39(36 \%)$ & $15(32 \%)$ & .56 \\
\hline LVEF, \% & $54 \pm 15$ & $54 \pm 17$ & 1.00 \\
\hline Side of AV fistula, $\mathrm{n}(\%)$ & & & $<.001$ \\
\hline Right & $6(6 \%)$ & $21(45 \%)$ & \\
\hline Left & $102(94 \%)$ & $26(55 \%)$ & \\
\hline Location of AV fistula, $\mathrm{n}(\%)$ & & & .57 \\
\hline Upper arm & $11(10 \%)$ & $7(15 \%)$ & \\
\hline Forearm & $97(90 \%)$ & $40(85 \%)$ & \\
\hline Construction of AV fistula, $\mathrm{n}(\%)$ & & & .95 \\
\hline Direct anastomosis & $94(87 \%)$ & $40(85 \%)$ & \\
\hline Prosthetic graft & $14(13 \%)$ & $7(15 \%)$ & \\
\hline
\end{tabular}

1.18-7.85; $P=.04)$ emerged as predictor of hospital mortality.

\section{Late Outcomes}

During the follow-up period of $55 \pm 42$ months (median, 4.2 years) for 139 survivors, $58(42 \%)$ patients died and 42 $(30 \%)$ had MACE. The causes of late death included cardiac $(\mathrm{n}=24,41 \%)$, gastrointestinal $(\mathrm{n}=8,14 \%)$, infection $(\mathrm{n}=8,14 \%)$, stroke $(\mathrm{n}=7,12 \%)$, exacerbation of peripheral artery disease $(\mathrm{n}=5)$, cancer $(\mathrm{n}=5)$, and unknown $(\mathrm{n}=1)$. The overall actuarial survivals were $76.9 \%$ and $60.0 \%$ at 3 and 5 years, respectively. Median survival was 7.0 years. The MACE-free rates were $77.0 \%$ and $70.1 \%$ at 3 and 5 years, respectively. Among them, $102(73 \%)$ patients, $97(75 \%)$ in the ipsilateral group and $29(70 \%)$ in the contralateral group, used the AV fistula of the same side during the follow-up period, whereas the others switched to HD through a contralateral side fistula. According to the side of $\mathrm{AV}$ fistula, overall survival estimates were similar between the ipsilateral and contralateral groups $(P=.90)$, as shown in Figure 1. Also, there was no statistically significant difference in MACE-free rate between the 2 groups $(P=.07)$, as shown in Figure 2.

A Cox proportional hazards model adjusting for 6 covariates, including age greater than 65 years, DM, peripheral
TABLE 2. Operative data

\begin{tabular}{|c|c|c|c|}
\hline & $\begin{array}{c}\text { Ipsilateral } \\
(\mathbf{n}=\mathbf{1 0 8})\end{array}$ & $\begin{array}{c}\text { Contralateral } \\
(n=47)\end{array}$ & $P$ valu \\
\hline Emergency, n (\%) & $24(22 \%)$ & $11(23 \%)$ & .93 \\
\hline CABG & & & .79 \\
\hline Conventional, n (\%) & $41(38 \%)$ & $12(26 \%)$ & \\
\hline On-pump beating, n (\%) & $18(17 \%)$ & $13(27 \%)$ & \\
\hline Off-pump, n (\%) & $49(45 \%)$ & $22(47 \%)$ & \\
\hline Anastomosis & $2.8 \pm 1.0$ & $2.9 \pm 0.9$ & .55 \\
\hline LITA use, n (\%) & $108(100 \%)$ & $43(91 \%)$ & .002 \\
\hline To LAD, n (\%) & $101(93 \%)$ & $21(45 \%)$ & $<.001$ \\
\hline To diagonal branch, $\mathrm{n}(\%)$ & $11(10 \%)$ & $10(21 \%)$ & .10 \\
\hline To LCX, n (\%) & $8(7 \%)$ & $22(47 \%)$ & $<.001$ \\
\hline Sequential, n (\%) & $16(15 \%)$ & $12(24 \%)$ & .13 \\
\hline RITA use, n (\%) & $26(24 \%)$ & $28(60 \%)$ & $<.001$ \\
\hline To LAD, n (\%) & $5(5 \%)$ & $22(47 \%)$ & $<.001$ \\
\hline To diagonal branch, n (\%) & $1(1 \%)$ & $3(6 \%)$ & .06 \\
\hline To LCX, n (\%) & $14(13 \%)$ & $5(11 \%)$ & .46 \\
\hline To RCA, n (\%) & $7(6 \%)$ & $2(4 \%)$ & .51 \\
\hline Sequential, n (\%) & $2(2 \%)$ & $6(13 \%)$ & .004 \\
\hline GEA use, n (\%) & $27(25 \%)$ & $10(20 \%)$ & .45 \\
\hline To LCX, n (\%) & $5(5 \%)$ & $1(2 \%)$ & .41 \\
\hline To RCA, n (\%) & $25(23 \%)$ & $10(20 \%)$ & .62 \\
\hline Sequential, n (\%) & $5(5 \%)$ & $2(4 \%)$ & .84 \\
\hline SVG use, n (\%) & $66(61 \%)$ & $27(53 \%)$ & .33 \\
\hline To diagonal branch, $\mathrm{n}(\%)$ & $9(8 \%)$ & $3(6 \%)$ & .31 \\
\hline To LCX, n (\%) & $42(39 \%)$ & $11(23 \%)$ & .06 \\
\hline To RCA, n (\%) & $52(48 \%)$ & $23(45 \%)$ & .89 \\
\hline Sequential, n (\%) & $37(34 \%)$ & $10(20 \%)$ & .09 \\
\hline Bilateral ITA use, n (\%) & $27(25 \%)$ & $22(47 \%)$ & .004 \\
\hline All arterial conduits, $\mathrm{n}(\%)$ & $42(39 \%)$ & $24(51 \%)$ & .15 \\
\hline
\end{tabular}

$C A B G$, Coronary artery bypass grafting; LITA, left internal thoracic artery; $L A D$, left anterior descending artery; $L C X$, left circumflex artery; RITA, right internal thoracic artery; $R C A$, right coronary artery; $S V G$, saphenous vein graft; $I T A$, internal thoracic artery; GEA, gastroepiploic artery.

artery disease, LVEF less than $40 \%$, and postoperative mediastinitis, revealed that ipsilateral ITA grafting to the LAD was not a predictor for late death (Table 4). The variables of age less than 65 years, DM, and peripheral artery disease emerged as statistically significant predictors of late death. Also, after adjusting for 6 covariates, DM, LVEF less than

TABLE 3. Early outcomes

\begin{tabular}{lccc}
\hline & $\begin{array}{c}\text { Ipsilateral } \\
(\mathbf{n = 1 0 8})\end{array}$ & $\begin{array}{c}\text { Contralateral } \\
(\mathbf{n = 4 7 )}\end{array}$ & $\boldsymbol{P}$ value \\
\hline Hospital death, n (\%) & $11(10.2 \%)$ & $5(10.6 \%)$ & .93 \\
$\quad$ Cardiac & 3 & 1 & .63 \\
$\quad$ Non-cardiac & 8 & 4 & \\
Mediastinitis, n (\%) & $13(12.0 \%)$ & $8(17.0 \%)$ & .40 \\
CVVH use, n (\%) & $16(14.8 \%)$ & $11(23.4 \%)$ & .19 \\
Stroke, n (\%) & $2(1.9 \%)$ & $1(2.0 \%)$ & .96 \\
Survivors & & & \\
$\quad$ ICU stay, d (median) & $2.7 \pm 6.5(2)$ & $3.1 \pm 5.1(2)$ & .67 \\
$\quad$ Hospital stay, d (median) & $28 \pm 33(18)$ & $35 \pm 42(19)$ & .30 \\
\hline
\end{tabular}

$\mathrm{CVVH}$, Continuous veno-venous hemofiltration; $I C U$, intensive care unit. 


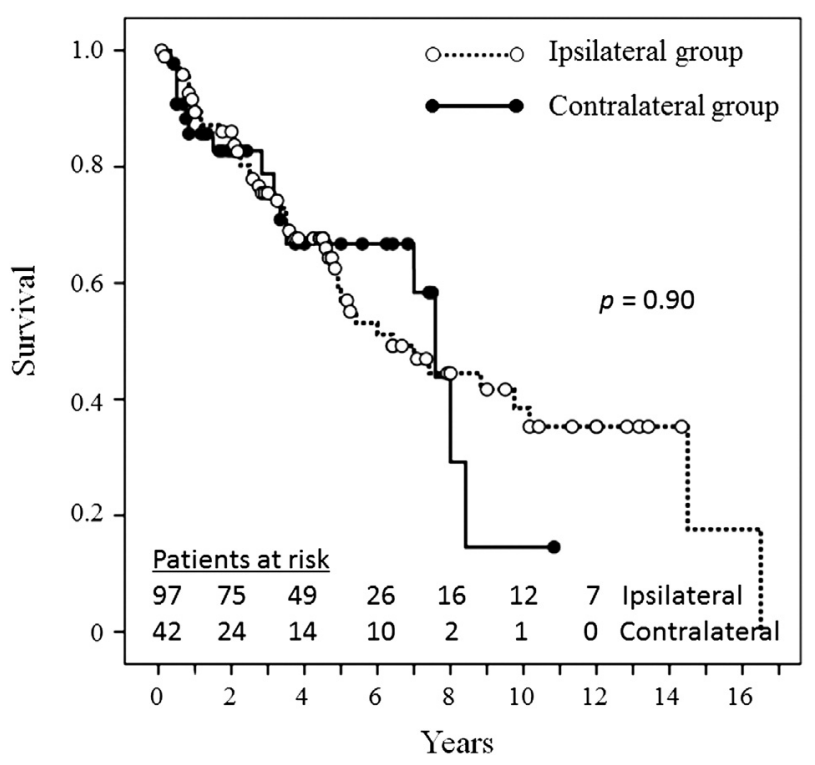

FIGURE 1. Estimated overall survival in the Kaplan-Meier model for patients whose left anterior descending artery (LAD) was revascularized with the internal thoracic artery (ITA) ipsilateral to the arteriovenous fistula (ipsilateral group, dotted line) and patients whose LAD was grafted with the ITA opposite to the fistula (contralateral group, solid line).

$40 \%$, use of saphenous vein graft, ipsilateral ITA grafting to the LAD was not a predictor for late MACE. DM and LVEF less than $40 \%$ were the independent predictors of late MACE.

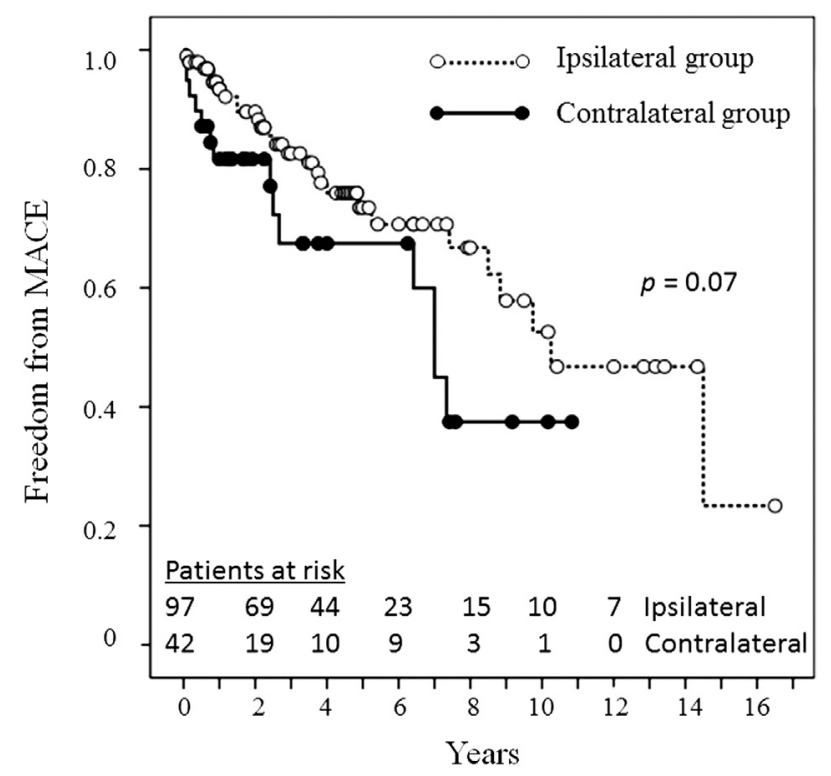

FIGURE 2. Estimated freedom from major adverse cardiac events $(M A C E)$ in the Kaplan-Meier model for patients whose left anterior descending artery (LAD) was revascularized with the internal thoracic artery (ITA) ipsilateral to the arteriovenous fistula (ipsilateral group, dotted line) and patients whose LAD was grafted with the ITA opposite to the fistula (contralateral group, solid line).
TABLE 4. Predictors for late death and MACE

\begin{tabular}{lccc}
\hline & Hazard ratio & $\mathbf{9 5} \%$ CI & $\boldsymbol{P}$ value \\
\hline All-cause death & & & \\
$\quad$ Age $>65$ y & 1.84 & $1.65-5.23$ & .035 \\
Diabetes mellitus & 3.14 & $1.51-6.53$ & .002 \\
PAD & 1.27 & $1.07-8.64$ & .042 \\
LVEF $<40 \%$ & 0.99 & $0.98-1.01$ & .586 \\
Postoperative mediastinitis & 1.072 & $0.46-2.51$ & .873 \\
Ipsilateral ITA graft to LAD & 0.53 & $0.24-1.17$ & .227 \\
MACE & & & \\
Diabetes mellitus & 3.11 & $1.50-6.45$ & .004 \\
LVEF <40\% & 2.46 & $1.18-8.43$ & .036 \\
SVG use & 0.93 & $0.47-1.82$ & .421 \\
CPB use & 1.08 & $0.38-2.51$ & .755 \\
Ipsilateral ITA graft to LAD & 0.73 & $0.24-1.84$ & .114 \\
\hline
\end{tabular}

$M A C E$, Major adverse cardiac events; $C I$, confidence interval; $P A D$, peripheral artery disease; $L V E F$, left ventricular ejection fraction; ITA, internal thoracic artery; $L A D$, left anterior descending artery; $S V G$, saphenous vein graft; $C P B$, cardiopulmonary bypass.

\section{DISCUSSION}

The key finding of this study was that revascularization of the LAD using the ITA graft ipsilateral to the AV fistula raises neither the operative mortality nor the risks of late death and MACE after isolated CABG in HD patients. We focused the surgical revascularization of the LAD, which is the most important for clinical outcomes of the HD patients, as well as of the non-HD patients. To our knowledge, this is the first report to assess the effects of the side of ITA graft, ipsilateral or contralateral to the AV fistula, on outcomes after CABG. Although no specific investigations of coronary steal were performed, our results may answer to the concerns of HD-induced reduction of ipsilateral ITA flow as a potential cause of poor outcomes in HD patients after CABG. ${ }^{12-15,17-19}$

In HD patients, the ascending aorta is often subject to severe atherosclerotic changes, constituting a dangerous source of systemic emboli after proximal anastomosis. $^{20,21}$ The use of in situ ITAs is strongly recommended to minimize aortic manipulation during CABG. However, Gaudino and colleagues ${ }^{14}$ showed hemodynamically evident ITA flow steal and consequent myocardial hypokinesia on transthoracic echocardiography during HD in 5 patients with ipsilateral AV fistula and ITA graft. In contrast, Rahbar and colleagues ${ }^{22}$ reported, in 15 HD patients, no significant changes in Doppler flow of either the ipsilateral or contralateral ITA with the AV fistula occluded and during HD. According to the previous reports of survival in HD patients after isolated CABG, ${ }^{12-15,17-19}$ the 5-year survivals were $50 \%$ to $60 \%$ and apparently lower than those in non-HD patients. Our study showed that such poor prognosis of HD patients is not associated with the side of the ITA graft to the LAD, which may be closely related to the concerned ITA flow steal on the same side as the AV fistula. 
The high mortality after CABG in HD patients may result from more diffuse coronary artery disease with poor runoff. However, Wong and associates ${ }^{23}$ quantitatively showed that HD patients undergoing CABG did not have a greater coronary artery atherosclerosis burden than matched controls. Therefore, the high mortality in HD patients may attribute to their extracardiac multiple comorbid disorders, including ventricular hypertrophy, cerebrovascular and peripheral artery disease, anemia, infection, electrolyte disturbances, cachexia, and increase in oxidative stress. ${ }^{24}$

The first limitation of this study is a retrospective design with a small sample size and a single-center experience. This observational study has produced a negative finding and may be underpowered. A power analysis using Power and Sample Size Calculation version 3.0 at Vanderbilt University, ${ }^{25}$ which may be downloaded for free, showed that a sample size of 159 and 333 patients would have a power of 0.8 and $\alpha$ value of $5 \%$ to detect a 2 -year difference in overall survival and MACE, respectively. Therefore, this study was underpowered for MACE, but for survival. Larger prospective studies of $\mathrm{HD}$ patients undergoing CABG are needed to identify risk factors for potential AV fistula-ITA hemodynamic interference. Second, this study may not match the patients adequately. Nearly half of the contralateral group had bilateral ITA use. Our results may be affected by this difference in bilateral ITA utilization. However, our study was conducted on the premise that coronary steal of the LAD has a much more adverse effect on the late outcomes than that of the non-LAD arteries. In addition, we should note our finding that late outcomes of the ipsilateral group are similar to those of the contralateral group, which included more patients receiving bilateral ITAs. This finding suggests the less adverse effects of the ipsilateral ITA use on late outcomes. The third limitation is that approximately $30 \%$ of the study patients lost functionality of the AV fistula and consequently switched the side of the fistula over time. The changes of the side of the AV fistula may affect the results of the present study.

As suggested in this study, ITA flow steal may not occur during HD in a CABG patient with an ipsilateral ITA graft of average flow. However, we should recognize the risk factors known to predispose to ITA flow steal, such as altered ITA anatomy, subclavian stenosis, and anatomic location of the AV fistula. In addition, we should recognize that the blood flow through the AV fistula increases with time, associated with potential risk of ITA flow steal. Furthermore, when the long-term HD patients require additional AV fistulas, we must consider what kind of graft conduit is used. On the other hand, as Baciewicz and Harris ${ }^{12}$ and Baciewicz alone ${ }^{15}$ recommend, an AV fistula with high flow volume, for example, a bridge fistula with a prosthetic graft or more proximal fistula in the upper extremity, should not be constructed in patients with ipsilateral ITA grafts.
In conclusion, revascularization of the LAD using an in situ ITA graft ipsilateral to the AV fistula increases neither the operative mortality nor the risks of late death and MACE after isolated CABG in HD patients. Our results may provide important information regarding the choice of CABG graft conduits and the management of the HD patients after CABG.

\section{References}

1. US Renal Data System. USRDS 2006 Annual Data Report: atlas of end-stage renal disease in the United States. Available at: http://www.usrds.org/atlas_2010. htm. Accessed April 1, 2012.

2. An overview of regular dialysis treatment in Japan as of December 31, 2010. Japanese Society for Dialysis Therapy. Available at http://docs.jsdt.or.jp/overview/ index.html. Accessed April 1, 2012

3. Ashrith G, Elayda MA, Wilson JM. Revascularization options in patients with chronic kidney disease. Tex Heart Inst J. 2010;37:9-18.

4. Hillis LD, Smith PK, Anderson JL, Bittl JA, Bridges CR, Byrne JG, et al. 2011 ACCF/AHA Guideline for Coronary Artery Bypass Graft Surgery: a report of the American College of Cardiology Foundation/American Heart Association Task Force on Practice Guidelines. Circulation. 2011;124:e652-735.

5. Herzog CA, Ma JZ, Collins AJ. Comparative survival of dialysis patients in the United States after coronary angioplasty, coronary artery stenting, and coronary artery bypass surgery and impact of diabetes. Circulation. 2002;106:2207-11.

6. Sunagawa G, Komiya T, Tamura N, Sakaguchi G, Kobayashi T, Murashita T. Coronary artery bypass surgery is superior to percutaneous coronary intervention with drug-eluting stents for patients with chronic renal failure on hemodialysis. Ann Thorac Surg. 2010;89:1896-900.

7. Terazawa S, Tajima K, Takami Y, Tanaka K, Okada N, Usui A, et al. Early and late outcomes of coronary artery bypass surgery versus percutaneous coronary intervention with drug-eluting stents for dialysis patients. J Card Surg. 2012; 27:281-7.

8. Nakayama Y, Sakata R, Ura M. Bilateral internal thoracic artery use for dialysis patients: does it increase operative risk? Ann Thorac Surg. 2001;71:783-7.

9. Beckermann J, Camp JV, Li S, Wahl SK, Collins A, Herzog CA. On-pump versus off-pump coronary surgery outcomes in patients requiring dialysis: perspectives from a single center and the United States experience. J Thorac Cardiovasc Surg. 2006;131:1261-6.

10. Dewey TM, Herbert MA, Prince SL, Robbins CL, Worley CM, Magee MJ, et al Does coronary artery bypass graft surgery improve survival among patients with end-stage renal disease? Ann Thorac Surg. 2006;81:591-8.

11. Kai M, Okabayashi H, Hanyu M, Soga Y, Nomoto T, Nakano J, et al. Long-term results of bilateral internal thoracic artery grafting in dialysis patients. Ann Thorac Surg. 2007;83:1666-71.

12. Baciewicz FA, Harris RJ. Is "steal" present in hemodialysis patients with ipsilateral internal mammary graft? Ann Thorac Surg. 2002;73:349-50.

13. Kato H, Ikawa S, Hayashi A, Yokoyama K. Internal mammary artery steal in a dialysis patient. Ann Thorac Surg. 2003;75:270-1.

14. Gaudino M, Serricchio M, Luciani N, Giungi S, Salica A, Pola R, et al. Risks of using internal thoracic artery grafts in patients in chronic hemodialysis via upper extremity arteriovenous fistula. Circulation. 2003;107:2653-5.

15. Baciewics FA. Selection of dialysis patients for bilateral internal thoracic artery grafts. Ann Thorac Surg. 2007;84:1797.

16. Takami Y, Tajima K, Okada N, Fujii K, Sakai Y, Hibino M, et al. Simplified management of hemodialysis-dependent patients undergoing cardiac surgery. Ann Thorac Surg. 2009;88:1515-9.

17. Massad MG, Kpodonu J, Lee J, Espat J, Gandhi S, Tevar A, et al. Outcome of coronary artery bypass operations in patients with renal insufficiency with and without renal transplantation. Chest. 2005;128:855-62.

18. Rahmanian PB, Adams DH, Castillo JG, Vassalotti J, Filsoufi F. Early and late outcome of cardiac surgery in dialysis-dependent patients: single-center experience with 245 consecutive patients. J Thorac Cardiovasc Surg. 2008;135:915-22.

19. Takami Y, Tajima K, Kato W, Fujii K, Hibino M, Munakata H, et al. Predictors for early and late outcomes after coronary artery bypass grafting in hemodialysis patients. Ann Thorac Surg. 2012;94:1940-6.

20. Gaudino M, Glieca F, Alessandrini F, Luciani N, Cellini C, Pragliola C, et al. The unclampable ascending aorta in coronary artery bypass patients: a surgical challenge of increasing frequency. Circulation. 2000;102:1497-502. 
21. Takami Y, Tajima K, Terazawa S, Okada N, Fujii K, Sakai Y. Safer aortic crossclamping under short-time moderate hypothermic circulatory arrest for cardiac surgery in patients with a bad ascending aorta. J Thorac Cardiovasc Surg. 2009; 137:875-80.

22. Rahbar R, McGee WR, Birdas TJ, Muluk S, Magovern J, Maher T. Upper extremity arteriovenous fistulas induce modest hemodynamic effect on the in situ internal thoracic artery. Ann Thorac Surg. 2006;81:145-7.
23. Wong D, Thompson G, Buth K, Sullivan J, Ali I. Angiographic coronary diffuseness and outcomes in dialysis patients undergoing coronary artery bypass grafting surgery. Eur J Cardiothorac Surg. 2003;24:388-92.

24. Galle J. Oxidative stress in chronic renal failure. Nephrol Dial Transplant. 2001; 16:2135-7.

25. Power and sample size calculation version 3.0, 2009. Available at: http://biostat. mc.vanderbilt.edu/PowerSampleSize. Accessed November 1, 2012.

Access to The Journal of Thoracic and Cardiovascular Surgery Online is reserved for print subscribers!

Full-text access to The Journal of Thoracic and Cardiovascular Surgery Online is available for all print subscribers. To activate your individual online subscription, please visit The Journal of Thoracic and Cardiovascular Surgery Online, point your browser to http://www.mosby.com/jtcvs, follow the prompts to activate your online access, and follow the instructions. To activate your account, you will need your subscriber account number, which you can find on your mailing label (note: the number of digits in your subscriber account number varies from 6 to 10). See the example below in which the subscriber account number has been circled:

\section{Sample mailing label}

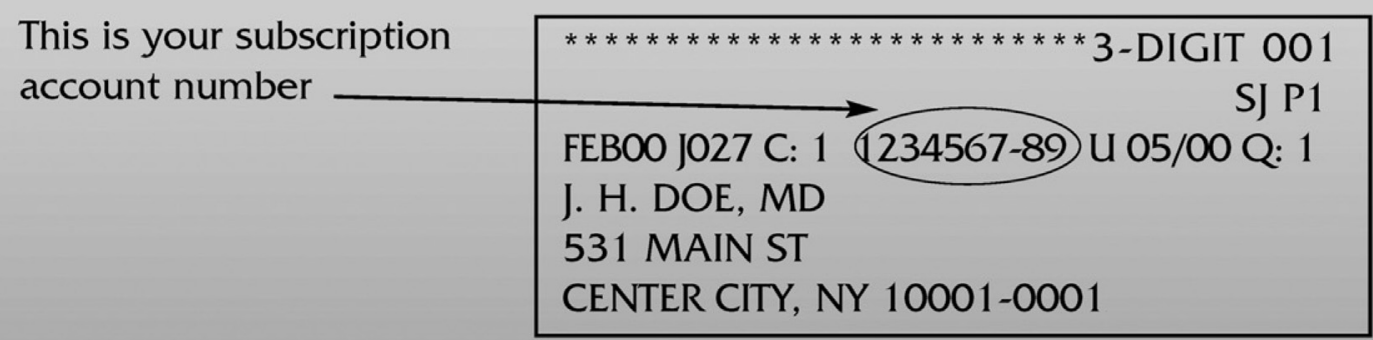

Personal subscriptions to The Journal of Thoracic and Cardiovascular Surgery Online are for individual use only and may not be transferred. Use of The Journal of Thoracic and Cardiovascular Surgery Online is subject to agreement to the terms and conditions as indicated online. 